\title{
ChAdOx1 nCoV-19 vaccine prevents SARS-CoV-2 pneumonia in rhesus macaques
}

https://doi.org/10.1038/s41586-020-2608-y

Received: 13 May 2020

Accepted: 24 July 2020

Published online: 30 July 2020

Check for updates

\begin{abstract}
Neeltje van Doremalen ${ }^{1,4}$, Teresa Lambe ${ }^{2,4}$, Alexandra Spencer ${ }^{2}$, Sandra Belij-Rammerstorfer ${ }^{2}$, Jyothi N. Purushotham ${ }^{1,2}$, Julia R. Port', Victoria A. Avanzato', Trenton Bushmaker', Amy Flaxman ${ }^{2}$, Marta Ulaszewska ${ }^{2}$, Friederike Feldmann ${ }^{3}$, Elizabeth R. Allen ${ }^{2}$, Hannah Sharpe ${ }^{2}$, Jonathan Schulz', Myndi Holbrook', Atsushi Okumura', Kimberly Meade-White', Lizzette Pérez-Pérez' ${ }^{1}$, Nick J. Edwards ${ }^{2}$, Daniel Wright ${ }^{2}$, Cameron Bissett ${ }^{2}$, Ciaran Gilbride ${ }^{2}$, Brandi N. Williamson', Rebecca Rosenke ${ }^{3}$, Dan Long ${ }^{3}$, Alka Ishwarbhai ${ }^{2}$, Reshma Kailath², Louisa Rose ${ }^{2}$, Susan Morris ${ }^{2}$, Claire Powers ${ }^{2}$, Jamie Lovaglio ${ }^{3}$, Patrick W. Hanley ${ }^{3}$, Dana Scott ${ }^{3}$, Greg Saturday ${ }^{3}$, Emmie de Wit', Sarah C. Gilbert ${ }^{2,5} \otimes$ \& Vincent J. Munster ${ }^{1,5 凶}$
\end{abstract}

\begin{abstract}
Severe acute respiratory syndrome coronavirus 2 (SARS-CoV-2) emerged in December $2019^{1,2}$ and is responsible for the coronavirus disease 2019 (COVID-19) pandemic ${ }^{3}$. Vaccines are an essential countermeasure and are urgently needed to control the pandemic ${ }^{4}$. Here we show that the adenovirus-vector-based vaccine ChAdOx1 nCoV-19, which encodes the spike protein of SARS-CoV-2, is immunogenic in mice and elicites a robust humoral and cell-mediated response. This response was predominantly mediated by type-1 $\mathrm{T}$ helper cells, as demonstrated by the profiling of the IgG subclass and the expression of cytokines. Vaccination with ChAdOx1 nCoV-19 (using either a prime-only or a prime-boost regimen) induced a balanced humoral and cellular immune response of type- 1 and type- $2 \mathrm{~T}$ helper cells in rhesus macaques. We observed a significantly reduced viral load in the bronchoalveolar lavage fluid and lower respiratory tract tissue of vaccinated rhesus macaques that were challenged with SARS-CoV-2 compared with control animals, and no pneumonia was observed in vaccinated SARS-CoV-2-infected animals. However, there was no difference in nasal shedding between vaccinated and control SARS-CoV-2-infected macaques. Notably, we found no evidence of immune-enhanced disease after viral challenge in vaccinated SARS-CoV-2-infected animals. The safety, immunogenicity and efficacy profiles of ChAdOx1 nCoV-19 against symptomatic PCR-positive COVID-19 disease will now be assessed in randomized controlled clinical trials in humans.
\end{abstract}

ChAdOx1 is a replication-deficient simian adenoviral vector derived from isolate Y25. The seroprevalence of antibodies against Y25 in the human population was found to be $0 \%$ of tested individuals in the UK and $9 \%$ in The Gambia ${ }^{5}$. It was previously demonstrated that a single dose of ChAdOx1 MERS, which encodes the spike protein of Middle East respiratory syndrome coronavirus (MERS-CoV), protected non-human primates (NHPs) against MERS-CoV-induced disease ${ }^{6}$. After the emergence of SARS-CoV-2, we designed a similar ChAdOx1-vector-based vaccine that encodes the codon-optimized full-length spike protein of SARS-CoV-2.

\section{Immunogenicity in mice}

Two mouse strains (BALB/c $(n=5)$ and outbred CD1 $(n=8))$ were vaccinated intramuscularly with ChAdOx1 nCoV-19 or ChAdOx1GFP-a control vaccine that encodes green fluorescent protein (GFP). Humoral and cellular immunity responses were studied 9-14 days later. Total IgG titres were detected against the spike protein in all of the vaccinated mice (Fig. 1a). Profiling of the IgG subclasses showed a predominantly type-1 Thelper cell $\left(T_{H} 1\right)$ response after vaccination (Extended Data Fig. 1a) and induction of IgM antibodies (Extended Data Fig. 2a). Virus-specific neutralizing antibodies were detected in all mice vaccinated with ChAdOx1 nCoV-19, whereas no neutralization was detected in serum from mice vaccinated with ChAdOx1 GFP (Fig. 1b). Splenic T cell responses measured by IFN $\gamma$ ELISpot and intracellular cytokine staining were detected against peptides spanning the full length of the spike construct (Fig. 1c). Again, a strong $\mathrm{T}_{\mathrm{H}} 1$-type response was detected after vaccination as supported by high expression levels of IFN $\gamma$ and TNF, and low expression levels of IL-4 and IL-10 (Fig. 1d and Extended Data Fig. 1b, c).

\section{Immunogenicity in rhesus macaques}

We next evaluated the efficacy of ChAdOx $1 \mathrm{nCoV}-19$ in rhesus macaques, a NHP model that displays robust infection of the upper and lower

'Laboratory of Virology, National Institute of Allergy and Infectious Diseases, National Institutes of Health, Hamilton, MT, USA. ${ }^{2}$ The Jenner Institute, University of Oxford, Oxford, UK. ${ }^{3}$ Rocky

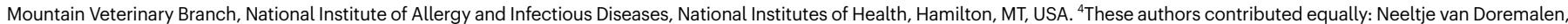
Teresa Lambe. ${ }^{5}$ These authors jointly supervised this work: Sarah C. Gilbert, Vincent J. Munster. ${ }^{\bowtie}$ e-mail: sarah.gilbert@ndm.ox.ac.uk; vincent.munster@nih.gov 

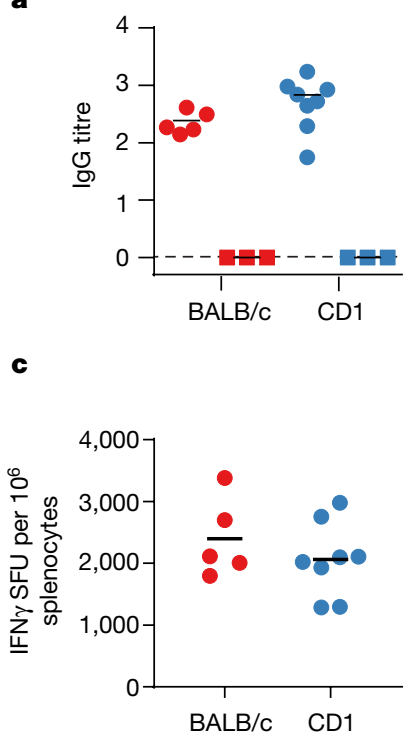

b
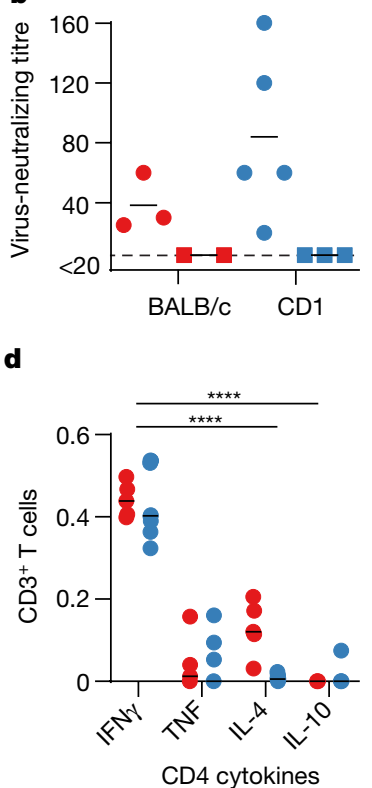

- BALB/c ChAdOx1 nCoV-19

BALB/c ChAdOx1 GFP

- CD1 ChAdOx1 nCoV-19

- CD1 ChAdOx1 GFP
Fig. 1 | Humoral and cellular immune responses to ChAdOx1 nCoV-19 vaccination in mice. a, Endpoint titre of serum IgG detected against the spike protein at 14 days after vaccination. No positive responses were detected in the control group. From left to right, $n=5,3,8$ and 3 mice were analysed in a single independent experiment. b, Virus-neutralizing titre in serum at 9 days after vaccination. From left to right, $n=3,2,5$ and 3 mice were analysed in a single independent experiment. c, Summed IFN $\gamma$ ELISpot responses in splenocytes to peptides that spanned the spike protein at 14 days after vaccination with ChAdOx1 nCoV-19. Control mice had low responses ( $<100$ spot-forming units $(\mathrm{SFU})$ ) (data not shown). $n=5$ and 8 mice were analysed in a single independent experiment. d, Summed frequency of spike-specific cytokine-positive CD3 ${ }^{+}$ T cells at 14 days after vaccination with ChAdOx $1 \mathrm{nCoV}-19$. $P$ values for the indicated comparisons were as follows: left, ${ }^{* * * *} P<0.0001$ (both comparisons); right, ${ }^{* * *} P=0.0002$ (IFN $\gamma$ and IL-4); ${ }^{* * *} P=0.0001$ (IFN $\gamma$ and IL-10); ${ }^{* *} P=0.0054$ (TNF and IL-4); ${ }^{* *} P=0.0022$ (TNF and IL-10). $n=5$ BALB/c and 8 CD1 mice were analysed in a single independent experiment. The dotted line indicates the limit of detection $(\mathbf{a}, \mathbf{b})$, the lines show the mean, squares and circles show the individual mice. Statistical significance was determined using two-way (repeated-measure) analysis of variance (ANOVA) and post hoc Tukey's test. respiratory tract and virus shedding after inoculation with SARS-CoV-2 ${ }^{7}$. Six animals per group were vaccinated using a prime-only regimen ( 28 days before challenge) or a prime-boost regimen ( 56 and 28 days before challenge) intramuscularly with $2.5 \times 10^{10} \mathrm{ChAdOx} 1 \mathrm{nCoV}-19$ virus particles each. As a control, six animals were vaccinated via the same route with the same dose of ChAdOx1 GFP (one animal was vaccinated 56 and 28 days before challenge and five animals were vaccinated 28 days before challenge) (Fig. 2a). No adverse events were observed after vaccination. Spike-specific antibodies were present as early as 14 days after vaccination and were significantly increased after the second immunization (two-tailed signed-rank Wilcoxon test). Endpoint IgG titres of 400-6,400 (prime) and 400-19,200 (prime-boost) were measured on the day of challenge (Fig. 2b). Virus-specific neutralizing antibodies were also significantly increased after secondary immunization (two-tailed signed-rank Wilcoxon test) and detectable in all vaccinated animals before challenge (5-40 (prime) and 10-160 (prime-boost)), whereas no virus-specific neutralizing antibodies were detected in control animals (Fig. 2c). IgM antibodies were present in the serum after vaccination on the day of the challenge in six out of six prime-boost and two out of six prime-only animals (Extended Data Fig. 2b). SARS-CoV-2 spike-specific T cell responses were detected on the day of challenge by IFN $\gamma$ ELISpot assay after the stimulation of peripheral blood mononuclear cells with a peptide library that spanned the full length of the spike protein. No statistically significant difference in the magnitude of the response was found between the prime-boost and prime-only group (Mann-Whitney $U$-test, $P=0.3723$ ) (Fig. 2d). As previously reported ${ }^{6}$, vaccination with ChAdOx 1 nCoV-19 resulted in the induction of neutralizing antibodies against the vaccine vector itself within 28 days of vaccination (Extended Data Fig. 3). Nonetheless, a boost vaccination with ChAdOx1 nCoV-19 resulted in a significant increase in binding and neutralizing antibodies in NHPs (Fig. 2b, c) and an increase in the SARS-CoV-2 virus-neutralizing titre was not significantly correlated with the ChAdOx1 virus-neutralizing titre (two-tailed Pearson correlation, $\left.r^{2}=0.6493 P=0.0529\right)$.

\section{Clinical signs}

After challenge with a 50\% tissue culture infective dose $\left(\mathrm{TCID}_{50}\right)$ of $2.6 \times 10^{6}$ of SARS-CoV- 2 in both the upper and lower respiratory tracts of rhesus macaques, the average clinical score of control animals was higher compared with ChAdOx1 nCoV-19-vaccinated animals. This was significantly different as determined using a Mann-Whitney $U$-test on 4-7 days post-infection (d.p.i.) (Fig. 3a).

\section{Viral load in respiratory tract samples}

In BAL fluid obtained from control animals, viral genomic RNA (gRNA) and subgenomic RNA (sgRNA), the latter of which is indicative of virus replication, were detected on all days. By contrast, viral gRNA and sgRNA were detected in only two vaccinated animals on 3 d.p.i., and the viral load was significantly lower (Fig. 3b). Viral gRNA was detected in nose swabs from all animals and no difference was found on any day between vaccinated and control animals. Viral sgRNA was detected in a minority of samples, with no difference between groups (Fig. 3c). Infectious virus could only be detected at 1 and 3 d.p.i. in prime-only vaccinated and control animals, and 1 d.p.i. in prime-boost vaccinated animals (Extended Data Table 1).

\section{Cytokine response}

Cytokines in serum were analysed after challenge to monitor immune responses. After vaccination, the levels of $\mathrm{T}_{\mathrm{H}} 1$ (IFN $\gamma$ and IL-2) or type-2 $\mathrm{T}$ 
a

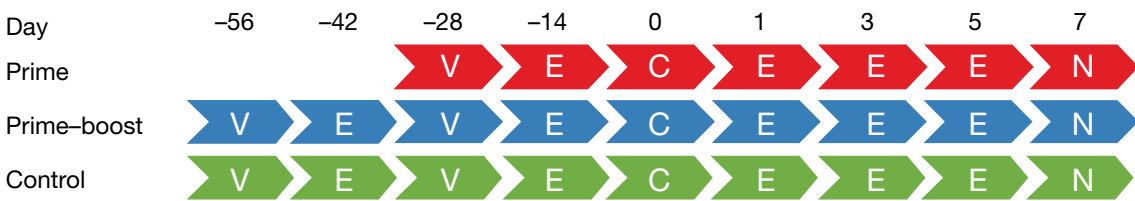

b

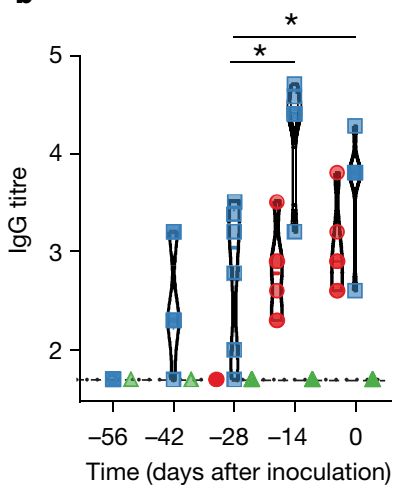

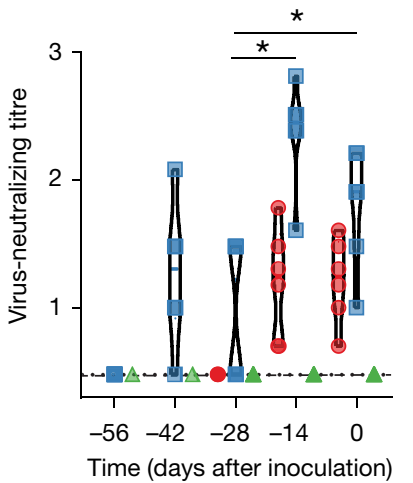

d

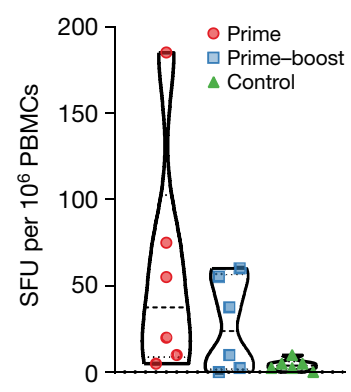

Fig. 2 | Humoral and cellular immune responses to ChAdOx1 nCoV-19 vaccination in rhesus macaques. a, Study schedule for NHPs. C, examination and challenge; $E$, examination; $N$, examination and necropsy; $V$, vaccination. b, Endpoint IgG titre in serum against trimeric spike protein. $\log _{10}$-transformed IgG endpoint titrations are shown, which were obtained by enzyme-linked immunosorbent assay (ELISA). c, $\log _{10}$-transformed virus-neutralizing titres in the serum.d, Summed IFN $\gamma$ ELISpot responses in peripheral blood mononuclear cells collected on the day of challenge to peptides that span the full length of the spike protein. Red circles, prime-only vaccine; blue squares, prime-boost vaccine; green triangles, controls. The dotted line shows the limit of detection. ${ }^{*} P=0.0313$. Statistical significance was determined using two-tailed signed-rank Wilcoxon tests. helper cell $\left(\mathrm{T}_{\mathrm{H}} 2\right)$ (IL-4, IL-5 or IL-13) cytokines in the serum of NHPs were low and no evidence of a dominant $\mathrm{T}_{\mathrm{H}} 2$ response was detected (Extended Data Fig. 4). We observed a significant upregulation in IFN $\gamma$ at 1 d.p.i. in ChAdOx1 $\mathrm{nCoV}$-19 prime-only-vaccinated animals, but not in prime-boost-vaccinated or control animals. IL-10 and IL-13 were significantly upregulated in control animals compared with primeboost-vaccinated animals on 1 and 7 d.p.i. (IL-13 only), but not compared with prime-only-vaccinated animals. No significant differences were observed between ChAdOx1 nCoV-19-treated and control animals for TNF, IL-2, IL-4, IL-5 and IL-6 (Extended Data Fig. 4); this is consistent with a previously observed lack of upregulation of cytokines and chemokines in rhesus macaques after infection with SARS-CoV-2.

\section{Pulmonary pathology and viral load}

At 7 d.p.i., all animals were euthanized, and tissues were collected. None of the vaccinated monkeys developed pulmonary pathology after inoculation with SARS-CoV-2. All lungs were histologically normal and no evidence of viral pneumonia nor immune-enhanced inflammatory disease was observed. In addition, noSARS-CoV-2 antigen was detected by immunohistochemistry in the lungs of any of the vaccinated animals. Three out of six control animals developed some degree of viral interstitial pneumonia. Lesions were widely separated and characterized by thickening of alveolar septae by small amounts of oedema fluid and few macrophages and lymphocytes. Alveoli contained small numbers of pulmonary macrophages and, rarely, oedema. Type-II pneumocyte hyperplasia was observed. Multifocal, perivascular infiltrates of small numbers of lymphocytes that formed perivascular cuffs were observed. Immunohistochemistry analysis showed the presence of viral antigen in type-I and II pneumocytes, as well as in alveolar macrophages, in five out of six control animals (Fig. 4). We were unable to detect any lesions or immunohistochemistry-positive cells in nasal mucosa in any of the animals.

The viral gRNA load was high in the lung tissues of all control animals and viral sgRNA was detected in five out of six control animals (Fig. 3d). In the prime-only-vaccinated group, the viral gRNA load was significantly lower in lung tissues as determined using a MannWhitney's $U$-test, and below the limit of detection in two out of six vaccinated animals; viral sgRNA was detected only in the lung tissue of one animal (Fig. 3d and Extended Data Fig. 5). In the prime-boost-vaccinated group, viral gRNA was detected in two out of six animals; one animal was weakly positive in one lung lobe and one animal, which mounted a limited response to vaccination, was positive in four lung lobes. Viral sgRNA could only be detected in lung tissue from the animal with a lower immune response (Fig. 3d and Extended Data Fig. 5). We did not detect infectious virus in any lung tissue.

\section{Extrapulmonary pathology and viral load}

No lesions were observed in gastrointestinal tissues of any animals. As previously reported ${ }^{7}$, SARS-CoV-2 antigen could be detected in lymphocytes and macrophages in the lamina propria of the intestinal tract of all control animals. This phenomenon was also observed in six out of six prime-only-vaccinated animals and three out of six prime-boost-vaccinated animals. There were no histological differences between lymphoid tissues of vaccinated or control animals.

Viral gRNA could be detected in extrarespiratory tissues but was predominantly low in all animals and not associated with the detection of sgRNA. The viral gRNA load in intestinal tissues of primeboost-vaccinated animals was higher than the levels measured in control and prime-only-vaccinated animals and was associated with the detection of sgRNA. However, no infection of intestinal tissue was observed by immunohistochemistry, nor were we able to detect infectious virus in intestinal tissue (Extended Data Fig. 6).

\section{Discussion}

Here we show that a single vaccination with ChAdOx1 nCoV-19 is effective in preventing damage to the lungs after challenging NHPs with a high dose of SARS-CoV-2 to both upper and lower respiratory tract, and a prime-boost regimen significantly increased humoral immune responses. We did not observe an increase in cellular responses after a 


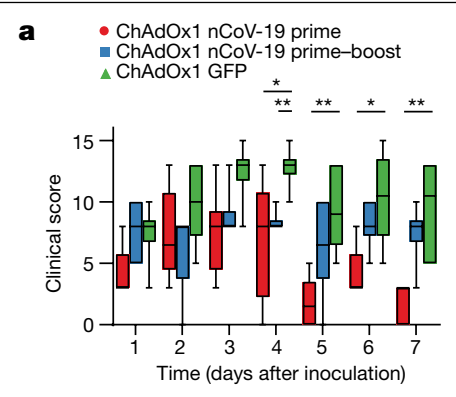

b

C
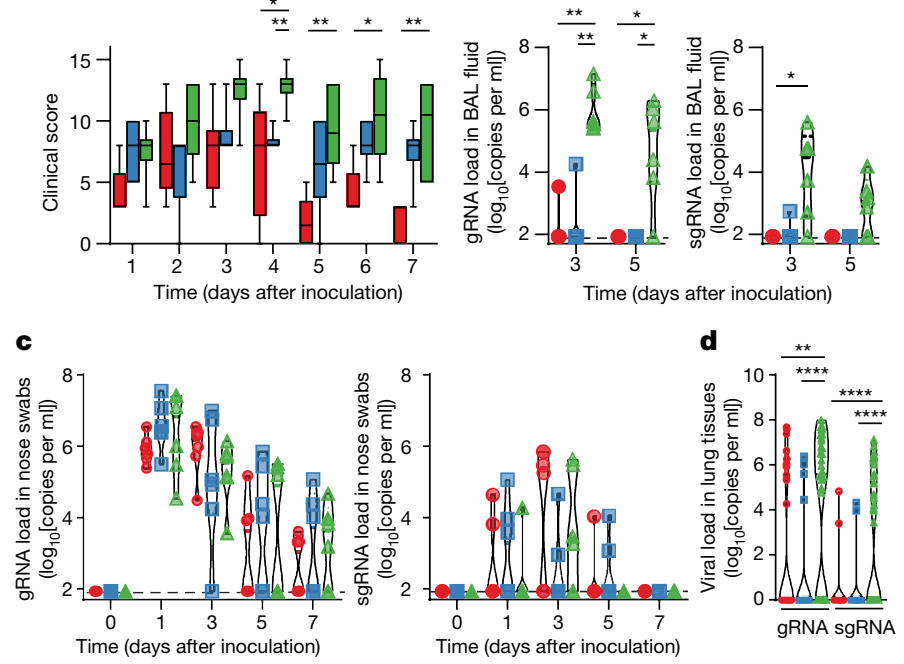

Fig. 3 | Clinical signs and viral load in rhesus macaques inoculated with SARS-CoV-2 after vaccination with ChAdOx1 nCoV-19. a, Clinical score in NHPs. Boxes show the 25th to 75 th percentiles, the centre line is the median and whiskers range from the 5 th to 95 th percentiles. $n=6$ animals per group were analysed in two independent experiments. $P$ values for the indicated comparisons were as follows: $P=0.0238$ (prime and control, 4 d.p.i.); $P=0.0043$ (prime-boost and control, 4 d.p.i.); $P=0.0043$ (prime and control, 5 d.p.i.); $P=0.0152$ (prime and control, 6 d.p.i.); $P=0.0022$ (prime and control, 7 d.p.i.). b, c, Viral load in BAL fluid $(\mathbf{b})\left({ }^{*} P=0.0152 ;{ }^{* *} P=0.0022\right)$ and nose swabs $(\mathbf{c})$ obtained from rhesus macaques. d, Viral load in lung tissue. $n=6$ lung lobes of six animals per group analysed in two independent experiments. ${ }^{* *} P=0.0011$; ${ }^{* * * *} P<0.0001$. The dotted line indicates the limit of detection. Statistical significance was determined using two-tailed Mann-Whitney $U$-tests. second dose of ChAdOx1 nCoV-19, in line with results reported in a previously published study, in which a homologous prime-boost regimen with malaria vaccine candidate ChAd63 ME-TRAP was used ${ }^{8}$. A small decrease in spike- and vector-specific antibody titres was observed between 14 days before challenge and the day of challenge in the prime-boost group. Longitudinal preclinical and clinical studies will investigate whether this decline in antibody titre is significant over time.

Two recently published SARS-CoV-2 vaccine studies in NHPs showed similar results: the first used a three-dose vaccination regimen of a high dose of whole inactivated SARS-CoV-2, which protected rhesus macaques from SARS-CoV-2 pneumonia ${ }^{9}$; and the second used a two-dose vaccination regimen with a DNA vaccine that encodes the spike protein, which significantly reduced viral RNA presence in BAL fluid and nasal swabs ${ }^{10}$. These three studies were conducted at different locations using different protocols, and therefore a direct comparison is difficult. Animals were challenged with $1 \times 10^{6} \mathrm{TCID}_{50}$ by the intratracheal route ${ }^{9}$, with $1.1 \times 10^{4}$ plaque-forming units via the intratracheal and intranasal route ${ }^{10}$ or, in this study, with $2.6 \times 10^{6} \mathrm{TCID}_{50}$ via intratracheal, intranasal, ocular and oral routes. The virus-neutralizing titres induced in vaccinated animals were similar between studies; vaccination with 2 doses of ChAdOx1 nCoV-19 resulted in a median virus-neutralizing titre of 80 determined in an inhibitory concentration (IC) ${ }_{100}$ assay. In other studies, 3 doses of $6 \mu \mathrm{g}$ inactivated SARS-CoV- 2 and 2 doses of spike-encoding DNA resulted in median virus-neutralizing titres of 50 and 74 , respectively, measured in an $\mathrm{IC}_{50}$ assay. A priming vaccination with ChAdOx1 nCoV-19 resulted in virus-neutralizing titres similar to those obtained after inoculation of rhesus macaques with SARS-CoV- $2^{7}$. After vaccination with one or two doses of ChAdOx1 nCoV-19, the viral loads in BAL fluid and lung tissue of vaccinated animals were significantly reduced, which suggests that vaccination prevents or strongly reduces virus replication in the lower respiratory tract. Despite this marked difference in virus replication in the lungs, we did not observe a reduction in viral shedding from the nose in either the prime-only or prime-boost regimen. Notably, viral RNA in nose swabs from vaccinated
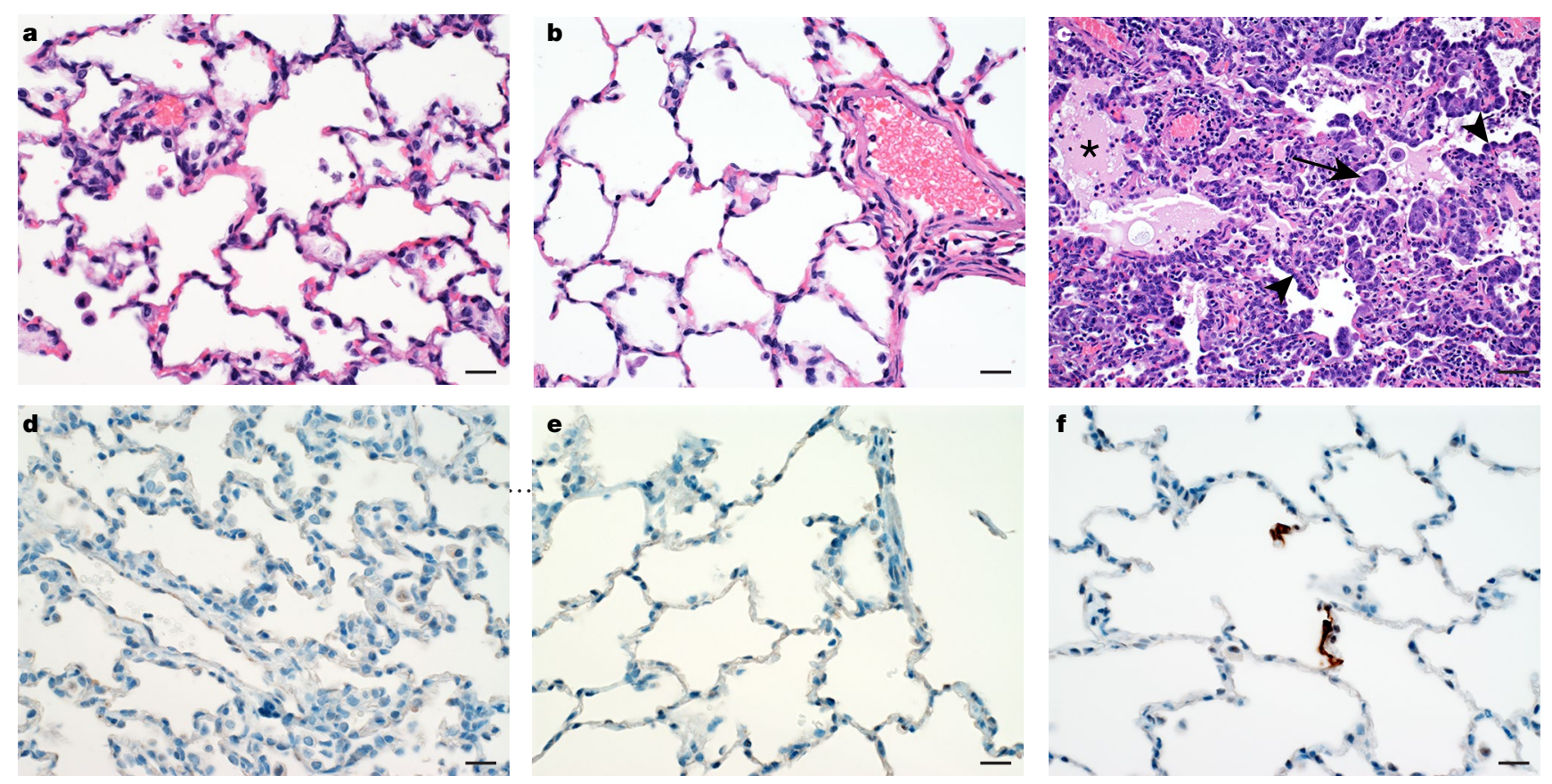

Fig. 4 | Histological changes in lungs of rhesus macaques on 7 d.p.i. a, b, No histological changes were observed in the lungs of ChAdOx1 nCoV-19 prime (a) and prime-boost (b) vaccinated animals. c, Interstitial pneumonia with oedema (asterisk), type-II pneumocyte hyperplasia (arrowheads) and syncytial cells (arrow) in control animals. d, e, No SARS-CoV-2 nucleoprotein antigen was detected by immunohistochemistry in the lungs of ChAdOx1 nCoV-19 prime-vaccinated (d) and prime-boost-vaccinated (e) animals. f, SARS-CoV-2 antigen (visible as red-brown staining) was detected by immunohistochemistry in type-I and type-II pneumocytes in the lungs of control animals. For each animal, 18 sections taken from 6 different lung lobes were evaluated; a representative lesion from each group is shown. Magnification, 400×; scale bars, $20 \mu \mathrm{m}$. 
animals was also detected in one study ${ }^{10}$, whereas the other study ${ }^{9}$ challenged only the lower respiratory tract with SARS-CoV-2 and therefore did not assess nasal shedding.

Our primary goal for a vaccine against SARS-CoV- 2 is to prevent disease, and we did not observe pneumonia or viral antigen in the lungs of vaccinated animals. On the basis of the data presented here, it is possible that a single or double dose of ChAdOx1 nCoV-19 will not prevent infection with or transmission of SARS-CoV-2. However, it could significantly reduce illness. Animals in this study were challenged with a high dose of virus using multiple routes as a stringent test of the protective efficacy of the vaccine and the absence of enhanced disease after infection. This does not reflect a realistic human exposure with regard to the route and dose. Future studies will determine whether changing the route of vaccination to expose mucosal surfaces will induce mucosal immunity, which may result in reduced nasal shedding and onward transmission. It should be noted that detection of sgRNA in nasal swabs was low with lower levels also detected in intestinal tissues. No viral antigen could be detected by immunohistochemistry, and it is not yet clear whether the virus is replicating in the nasal mucosa of vaccinated animals.

Several preclinical studies of vaccines against SARS-CoV resulted in immunopathology after vaccination and subsequent challenge, with more severe disease in vaccinated animals than in controls ${ }^{11-15}$. Immune-enhanced disease could be observed as early as 2 d.p.i. in mice ${ }^{14,15}$ and 7 d.p.i. in NHPs ${ }^{13}$. Immune-enhanced disease was associated with a $\mathrm{T}_{\mathrm{H}} 2$ response in mice ${ }^{14}$ and diffuse alveolar damage and cellular infiltrates in $\mathrm{NHPs}^{13}$. In this study, there was no evidence of immune-enhanced disease in vaccinated animals. The immune response was not skewed towards a $\mathrm{T}_{\mathrm{H}} 2$ response in mice or NHPs, there was no increase in clinical signs or virus replication throughout the study in vaccinated NHPs compared to controls and no markers of disease enhancement in pulmonary tissue of NHPs, such as an influx of cells or diffuse alveolar damage, were observed. The clinical scores of vaccinated animals were lower than the clinical scores in control animals, which strongly suggests that immune-enhanced disease was absent.

Results from ongoing clinical trials will be the most informative in determining whether ChAdOx1 nCoV-19 will be an appropriate vaccine candidate, but the results described in the present study are encouraging. The data presented here informed the start of a phase I clinical trial with ChAdOx1 nCoV-19 on 23 April 2020. As of 1 July 2020, more than 8,000 volunteers have participated in the randomized controlled clinical trials. This study is therefore an important step towards the development of a safe and efficacious SARS-CoV-2 vaccine.

\section{Online content}

Any methods, additional references, Nature Research reporting summaries, source data, extended data, supplementary information, acknowledgements, peer review information; details of author contributions and competing interests; and statements of data and code availability are available at https://doi.org/10.1038/s41586-020-2608-y.

1. Zhu, N. et al. A novel coronavirus from patients with pneumonia in China, 2019. N. Engl. J. Med. 382, 727-733 (2020).

2. Wu, F. et al. A new coronavirus associated with human respiratory disease in China. Nature 579, 265-269 (2020).

3. WHO. Coronavirus disease (COVID-19) Situation Report 113. https://www.who.int/docs/ default-source/coronaviruse/situation-reports/20200512-covid-19-sitrep-113. pdf?sfvrsn=feac3b6d_2 (2020).

4. Lurie, N., Saville, M., Hatchett, R. \& Halton, J. Developing COVID-19 vaccines at pandemic speed. N. Engl. J. Med. 382, 1969-1973 (2020).

5. Dicks, M. D. et al. A novel chimpanzee adenovirus vector with low human seroprevalence: improved systems for vector derivation and comparative immunogenicity. PLOS ONE 7, e40385 (2012).

6. van Doremalen, $\mathrm{N}$. et al. A single dose of ChAdOx1 MERS provides protective immunity in rhesus macaques. Sci. Adv. 6, eaba8399 (2020).

7. Munster, V. J. et al. Respiratory disease in rhesus macaques inoculated with SARS-CoV-2. Nature https://doi.org/10.1038/s41586-020-2324-7 (2020).

8. Bliss, C. M. et al. Assessment of novel vaccination regimens using viral vectored liver stage malaria vaccines encoding ME-TRAP. Sci. Rep. 8, 3390 (2018).

9. Gao, Q. et al. Development of an inactivated vaccine candidate for SARS-CoV-2. Science 369, 77-81 (2020).

10. $\mathrm{Yu}, \mathrm{J}$. et al. DNA vaccine protection against SARS-CoV-2 in rhesus macaques. Science 369, 806-811 (2020).

11. Weingartl, H. et al. Immunization with modified vaccinia virus Ankara-based recombinant vaccine against severe acute respiratory syndrome is associated with enhanced hepatitis in ferrets. J. Virol. 78, 12672-12676 (2004).

12. Bolles, M. et al. A double-inactivated severe acute respiratory syndrome coronavirus vaccine provides incomplete protection in mice and induces increased eosinophilic proinflammatory pulmonary response upon challenge. J. Virol. 85, 12201-12215 (2011).

13. Liu, L. et al. Anti-spike IgG causes severe acute lung injury by skewing macrophage responses during acute SARS-CoV infection. JCI Insight 4, e123158 (2019).

14. Tseng, C. T. et al. Immunization with SARS coronavirus vaccines leads to pulmonary immunopathology on challenge with the SARS virus. PLOS ONE 7, e35421 (2012).

15. Yasui, F. et al. Prior immunization with severe acute respiratory syndrome (SARS)-associated coronavirus (SARS-CoV) nucleocapsid protein causes severe pneumonia in mice infected with SARS-CoV. J. Immunol. 181, 6337-6348 (2008).

Publisher's note Springer Nature remains neutral with regard to jurisdictional claims in published maps and institutional affiliations.

(C) This is a U.S. government work and not under copyright protection in the U.S.; foreign copyright protection may apply 2020 


\section{Methods}

\section{Ethics statements}

Mice. Mice were used in accordance with the UK Animals (Scientific Procedures) Act under project licence number P9804B4F1 granted by the UK Home Office. Animals were housed in groups in individually ventilated cages under specific-pathogen-free conditions, at a constant temperature $\left(20-24^{\circ} \mathrm{C}\right)$ and humidity $(45-65 \%)$ with lighting on a fixed light/dark cycle (12-h/12-h).

NHPs. Approval for experiments involving NHPs was provided by the Institutional Animal Care and Use Committee (IACUC) at Rocky Mountain Laboratories. Animal experiments were carried out in an Association for Assessment and Accreditation of Laboratory Animal Care (AALAC)-approved facility by certified staff, following the basic principles and guidelines in the NIH Guide for the Care and Use of Laboratory Animals, the Animal Welfare Act, US Department of Agriculture and the US Public Health Service Policy on Humane Care and Use of Laboratory Animals. Rhesus macaques were housed in individual primate cages that enabled social interactions in a climate-controlled room with a fixed light/ dark cycle (12-h/12-h) and were monitored at least twice daily. Commercial monkey chow, treats and fruit were provided by trained personnel. Water was available ad libitum. Environmental enrichment consisted of a variety of human interactions, commercial toys, videos and music. The Institutional Biosafety Committee (IBC) approved work with infectious SARS-CoV-2 virus strains under BSL3 conditions. Virus inactivation of all samples was performed according to IBC-approved standard operating procedures for the removal of specimens from high containment areas.

\section{Generation of vaccine ChAdOx1 nCoV-19}

The spike protein of SARS-CoV-2 (GenBank accession number YP_009724390.1)-the surface glycoprotein responsible for receptor binding, fusion and entry into the host cell-was codon-optimized for expression in human cell lines and synthesized with the tissue plasminogen activator (tPA) leader sequence at the 5 ' end by GeneArt Gene Synthesis (Thermo Fisher Scientific). The sequence, which encodes amino acids 2-1273 of SARS-CoV-2 and the tPA leader, was cloned into a shuttle plasmid using InFusion cloning (Clontech). The shuttle plasmid encodes a modified human cytomegalovirus major immediate early promoter with tetracycline operator sites and a poly-adenylation signal from bovine growth hormone between Gateway recombination cloning sites. ChAdOx1 nCoV-19 was prepared using Gateway recombination technology (Thermo Fisher Scientific) between the shuttle plasmid described and the previously described ChAdOx1 destination DNABAC vector ${ }^{5}$, resulting in the insertion of the SARS-CoV-2 expression cassette at the E1 locus. The ChAdOx1 adenovirus genome was excised from the BAC using unique Pmel sites flanking the adenovirus genome sequence. The virus was rescued and propagated in T-Rex HEK293 cells (Invitrogen) in which antigen expression during virus propagation is repressed. Purification was carried out using $\mathrm{CsCl}$ gradient ultracentrifugation. Virus titres were determined by hexon immunostaining assay and viral particles were calculated on the basis of spectrophotometry ${ }^{16,17}$.

\section{Study design of animal experiments}

Mice. Female BALB/cOlaHsd (BALB/c) (Envigo) and outbred $\mathrm{Crl}: \mathrm{CD} 1$ (ICR) (CD1) (Charles River) mice of at least 6 weeks of age, were immunized by intramuscular injection in the musculus tibialis with $6 \times 10^{9}$ virus particles of ChAdOx1 nCoV-19 unless otherwise stated.

NHPs. Adult rhesus macaques (17 male and 1 female) between 2 and 4 years old were randomly divided into three groups of six animals. Animal group size was based on initial model development. Group 1 was vaccinated with ChAdOx1 nCoV-19 at -28 d.p.i., group 2 was vaccinated with ChAdOx1 nCoV-19 at -56 and -28 d.p.i., group 3 was vaccinated with ChAdOx1 GFP at -56 and -28 d.p.i. (1 animal) or at -28 d.p.i.
(5 animals). All vaccinations were done with $2.5 \times 10^{10}$ virus particles per animal diluted in sterile PBS. Blood samples were obtained before vaccination and 14 days afterwards. Animals were challenged with SARS-CoV-2 strain nCoV-WA1-2020 (MN985325.1) diluted in sterile DMEM on day 0; with administration of $4 \mathrm{ml}$ intratracheally, $1 \mathrm{ml}$ intranasally, $1 \mathrm{ml}$ orally and $0.5 \mathrm{ml}$ ocularly of $4 \times 10^{5} \mathrm{TCID}_{50} \mathrm{ml}^{-1}$ virus suspension. Animals were scored daily by the same person, who was blinded to study group allocations using a standardized scoring sheet. Scoring was based on the following criteria: general appearance, appearance of the skin and coat, discharge, respiration, appearance of the faeces and urine, appetite and activity. The scoring sheet can be found in a previously published study ${ }^{7}$. Clinical examinations were performed on $-28,-14,0,1,3,5$ and 7 d.p.i. Nasal swabs and blood were collected on all days that examinations were performed. BAL was obtained on 3, 5 and 7 d.p.i. by insertion of an endotracheal tube and bronchoscope into the trachea, then past the third bifurcation and subsequent addition of $10 \mathrm{ml}$ of sterile saline. Manual suction was applied to retrieve the BAL sample. Serum biochemistry (albumin, aspartate aminotransferase, alanine aminotransferase, $\gamma$-glutamyl transferase, blood urea nitrogen and creatinine) was analysed using the Vetscan VS2 Chemistry Analyzer and VetScan 2 Preventative Care 12 discs (Abaxis) (Supplementary Tables 1-3). Necropsy was performed on 7 d.p.i. and the following tissues were collected: cervical lymph node, mediastinal lymph node, conjunctiva, nasal mucosa, oropharynx, tonsil, trachea, all six lung lobes, right and left bronchus, heart, liver, spleen, kidney, stomach, duodenum, jejunum, ileum, caecum, colon and urinary bladder.

\section{Cells and virus}

SARS-CoV-2 strain nCoV-WA1-2020 (MN985325.1) was provided by the CDC. Virus propagation was performed in Vero E6 cells in DMEM supple-

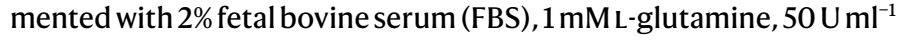
penicillin and $50 \mathrm{\mu g} \mathrm{ml}^{-1}$ streptomycin. The used virus stock was $100 \%$ identical to the initial deposited GenBank sequence (MN985325.1) and no contaminants were detected. Vero E6 cells were maintained in DMEM supplemented with $10 \% \mathrm{FBS}, 1 \mathrm{mML}$-glutamine, $50 \mathrm{U} \mathrm{ml}^{-1}$ penicillin and $50 \mu \mathrm{g} \mathrm{ml}^{-1}$ streptomycin. Vero E6 cells were provided by R. Baric and were not authenticated in-house; mycoplasma testing was performed at regular intervals and no mycoplasma was been detected.

\section{Virus isolation from tissue}

Tissue sections were weighed and homogenized in $1 \mathrm{ml}$ of DMEM. Then, $250 \mu \mathrm{l}$ of homogenate was added to Vero E6 cells in a 24-well plate in duplicate. After $1 \mathrm{~h}$ at $37^{\circ} \mathrm{C}$ and $5 \% \mathrm{CO}_{2}$, cells were washed with PBS and $500 \mu$ l of DMEM containing $2 \%$ FBS was added. Cells were incubated at $37^{\circ} \mathrm{C}$ and $5 \% \mathrm{CO}_{2}$. Cytopathogenic effects were assessed 6 days later.

\section{Virus neutralization assay for SARS-CoV-2}

Sera were heat-inactivated $\left(30 \mathrm{~min}, 56^{\circ} \mathrm{C}\right)$, twofold serial dilutions were prepared in $2 \%$ DMEM and 100 TCID $_{50}$ of SARS-CoV-2 was added. After $1 \mathrm{~h}$ incubation at $37^{\circ} \mathrm{C}$ and $5 \% \mathrm{CO}_{2}$, the virus:serum mixture was added to Vero $\mathrm{E} 6$ cells and incubated at $37^{\circ} \mathrm{C}$ and $5 \% \mathrm{CO}_{2}$. At 5 d.p.i., cytopathogenic effects were assessed. The virus neutralization titre was expressed as the reciprocal value of the highest dilution of the serum that still inhibited virus replication.

\section{Virus neutralization assay using ChAdOx1}

Chimpanzee adenovirus ChAdOx1-specific neutralizing antibody titres were assessed using a secreted placental alkaline phosphatase (SEAP) quantification assay as previously described ${ }^{6}$. In brief, GripTite MSR 293 cells (Invitrogen, R795-07) were infected with serially diluted serum in phenol-red-free DMEM (Life Technologies, 31053028) and the ChAdOx1-SEAP reporter virus in a 1:1 mixture for $1 \mathrm{~h}$ before replacing with phenol-red-free DMEM containing $10 \%$ FBS for $24 \mathrm{~h}$. For each sample, the SEAP concentration was assessed in 50- $\mu$ l aliquots of culture supernatant, with CPSD as an indicator substrate (Tropix Phospha-Light 
Chemiluminescent Assay Kit, Life Technologies, T1017). Luminescence intensity was measured using a Varioskan Flash luminometer (Thermo Fisher Scientific). Serum dilution neutralization titres were measured by linear interpolation of adjacent values (to $50 \%$ inhibition) to determine the serum dilution required to reduce the SEAP concentration by $50 \%$ compared to wells with virus alone.

\section{RNA extraction and quantitative reverse-transcription polymerase chain reaction}

Tissues (up to $30 \mathrm{mg}$ ) were homogenized in RLT buffer and RNA was extracted using the RNeasy kit (Qiagen) according to the manufacturer's instructions. RNA was extracted from BAL fluid and nasal swabs using the QiaAmp Viral RNA kit (Qiagen) according to the manufacturer's instructions. Viral gRNA-specific ${ }^{18}$ and sgRNA-specific ${ }^{19}$ assays were used for the detection of viral RNA. RNA $(5 \mu \mathrm{l})$ was tested with the Rotor-Gene probe kit (Qiagen) according to the manufacturer's instructions. Dilutions of SARS-CoV-2 standards with known genome copies were run in parallel.

\section{ELISA of mouse sera}

MaxiSorp plates (Nunc) were coated with S1 (monomeric, amino acids 1-674) or S2 (monomeric, amino acids 685-1211) (The Native Antigen Company; 50 ng per well) or with prefusion-stabilized SARS-CoV-2 spike protein $\left(250 \mathrm{ng}\right.$ per well) in PBS for overnight adsorption at $4{ }^{\circ} \mathrm{C}$. Plates were washed in PBS-Tween $(0.05 \% \mathrm{v} / \mathrm{v})$ and wells were blocked using casein (ThermoFisher Scientific) for $1 \mathrm{~h}$ at room temperature. Serially diluted mouse serum samples were added and incubated overnight at $4{ }^{\circ} \mathrm{C}$ or $37^{\circ} \mathrm{C}$ for $2 \mathrm{~h}$ for specific IgM detection. Plates were washed and alkaline phosphatase-conjugated goat anti-mouse IgG (Sigma) or $\operatorname{IgM}$ (Abcam) was added to all wells for $1 \mathrm{~h}$ at room temperature or $2 \mathrm{~h}$ at $37^{\circ} \mathrm{C}$. After washing the plates, pNPP substrate (Sigma) was added. Optical density (OD) values for each well were measured at $405 \mathrm{~nm}$. Endpoint titres were calculated as follows: the $\log _{10}(\mathrm{OD})$ against $\log _{10}$ (sample dilution) was plotted and a regression analysis of the linear part of this curve enabled calculation of the endpoint titre with an OD of three times the background. The same calculation was used to dilute the sera to the same amounts of total IgG for further testing on different IgG subclasses with anti-mouse IgG subclass-specific antibodies (Abcam). The results of the IgG subclass ELISA are presented using OD values.

\section{ELISA of NHP sera}

Prefusion-stabilized SARS-CoV-2 spike protein with a T4 fibritin trimerization motif ${ }^{20}$ was obtained from the Vaccine Research Centre. Maxisorp plates (Nunc) were coated overnight at $4{ }^{\circ} \mathrm{C}$ with 100 or $250 \mathrm{ng}$ spike protein per well in PBS for IgG and IgM detection, respectively. Plates were blocked with $100 \mu$ l of casein in PBS (Thermo Fisher) for $1 \mathrm{~h}$ at room temperature. Serum serially diluted $2 \times$ in casein in PBS was incubated at room temperature for $1 \mathrm{~h}$ or $37^{\circ} \mathrm{C}$ for $2 \mathrm{~h}$. IgG antibodies were detected using affinity-purified polyclonal antibody peroxidase-labelled goat-anti-monkey IgG (Seracare, 074-11-021) in casein and TMB two-component peroxidase substrate(Seracare,5120-0047), developed for 5-10 min and the reaction was stopped using stop solution (Seracare, 5150-0021) and read at $450 \mathrm{~nm}$. IgM antibodies were detected using anti-monkey alkaline phosphatase-conjugated antibodies after adding the pNPP substrate and measuring OD values at $405 \mathrm{~nm}$. All wells were washed $4 \times$ with PBST $0.1 \%$ Tween in between steps. The threshold for positivity was set at $3 \times$ the OD value of the negative control (serum obtained from NHPs before the start of the experiment) or 0.2 , whichever was higher, or at $3 \times$ the OD of the background for the calculation of the IgM endpoint values.

\section{ELISpot assay and intracellular cytokine staining analysis}

Single-cell suspensions of mouse splenocytes were prepared by passing cells through $70-\mu \mathrm{m}$ cell strainers and ACK lysis before resuspension in complete medium. Peripheral blood mononuclear cells (PBMCs) from rhesus macaques were isolated from ethylene diamine tetraaceticacid
(EDTA) whole blood using Leucosep tubes (Greiner Bio-one International) and Histopaque-1077 density-gradient cell-separation medium (Sigma-Aldrich) according to the manufacturers' instructions.

Mice. For analysis of IFN $\gamma$ production by ELISpot, cells were stimulated with pools of S1 or S2 peptides (final concentration of $2 \mu \mathrm{g} \mathrm{ml}^{-1}$ ) on IPVH-membrane plates (Millipore) coated with $5 \mu \mathrm{g} \mathrm{ml}^{-1}$ anti-mouse IFN $\gamma$ (AN18). After 18-20 h of stimulation, IFN $\gamma$ spot-forming cells were detected by staining membranes with anti-mouse IFN $\gamma$-biotin $\left(1 \mu \mathrm{g} \mathrm{ml}^{-1}\right)(\mathrm{R} 46 \mathrm{~A} 2)$ followed by streptavidin-alkaline phosphatase $\left(1 \mu \mathrm{g} \mathrm{ml}^{-1}\right)$ and development with an alkaline phosphatase conjugate substrate kit (BioRad).

For analysis of intracellular cytokine production, cells were stimulated at $37^{\circ} \mathrm{C}$ for $6 \mathrm{~h}$ with $2 \mu \mathrm{g} \mathrm{ml}^{-1} \mathrm{~S} 1$ or S2 pools of peptide, medium or a cell-stimulation cocktail (containing phorbol 12-myristate 13-acetate (PMA) and ionomycin, Biolegend), together with $1 \mu \mathrm{g} \mathrm{ml}^{-1}$ Golgi-plug (BD) with the addition of $2 \mu \mathrm{ml}^{-1} \mathrm{CD} 107 \mathrm{a}-\mathrm{Alexa} 647$. The cell supernatant was collected and frozen at $-20^{\circ} \mathrm{C}$ for subsequent analysis using a MesoScale Discovery (MSD) assay (see below). After cell-surface staining with CD4-BUV496, CD8-PerCPCy5.5, CD62L-BV711, CD127-BV650 and LIVE/DEAD Aqua, cells were fixed with $4 \%$ paraformaldehyde and stained intracellularly with TNF-A488, IL-2-PECy7, IL-4-BV605, IL-10PE and IFN $\gamma$-e450 diluted in Perm-Wash buffer (BD).

Sample acquisition was performed on a Fortessa (BD) and data were analysed in FlowJo V10 (TreeStar). An acquisition threshold was set at a minimum of 5,000 events in the live $\mathrm{CD}^{+}$gate. Antigen-specific T cells were identified by gating on LIVE/DEAD-negative, doublet-negative (FSC-H versus FSC-A), size (FSC-H versus SSC), $\mathrm{CD}^{+}, \mathrm{CD}^{+}$or $\mathrm{CD}^{+}$cells and cytokine-positive (the gating strategy is shown in Supplementary Fig. 1). Cytokine-positive responses are presented after subtraction of the background response detected in the corresponding unstimulated sample (medium containing CD107a and Golgi-plug) of each individual spleen sample. To determine whether there were statistically significant differences in the levels of cytokines produced by $\mathrm{CD}^{+}$or $\mathrm{CD} 8^{+} \mathrm{T}$ cells, data in each graph were analysed using a two-way (repeated-measure) ANOVA and post hoc Tukey's multiple comparison tests.

NHPs. For the IFN $\gamma$ ELISpot assay of PBMCs, cells were plated at a concentration of 100,000 cells per well and were stimulated with 4 contiguous peptide pools that spanned the length of the SARS-CoV-2 spike protein sequence at a concentration of $2 \mu \mathrm{g} \mathrm{ml}^{-1}$ per peptide (Mimotopes). The ImmunoSpot Human IFN $\gamma$ Single-Colour Enzymatic ELISpot Assay Kit was performed according to the manufacturer's protocol (Cellular Technology). ELISpot plates were inactivated in formalin overnight before removal from biosafety level 4 facilities for reading. Analysis was performed using the CTL ImmunoSpot Analyzer and ImmunoSpot Software (Cellular Technology). Spot-forming units per 1.0 $\times 10^{6} \mathrm{PBMCs}$ were summed across the four peptide pools for each animal.

\section{Measurement of cytokines and chemokines}

Mouse samples were assayed using the MSD Technology V-PLEX Mouse Cytokine 29-Plex kit according to the manufacturer's instructions. The NHP samples were inactivated with $\gamma$-radiation ( 2 MRad) according to standard operating procedures and assayed on a Bio-Plex 200 instrument (Bio-Rad) using the Non-Human Primate Cytokine MILLIPLEX map 23-plex kit (Millipore) according to the manufacturer's instructions. Lower limit of detection was used for all undetectable and extrapolated values. Only data for cytokines consistently above the lower limit of quantification were included in further analyses.

The $\log _{10}$-transformed fold change $\left(\log _{10}(\mathrm{FC})\right)$ for mouse samples was calculated as follows: $\log _{10}(\mathrm{FC})=\log _{10}\left[\left(\right.\right.$ stimulated $\left.\left(\mathrm{pg} \mathrm{ml}^{-1}\right)+1\right)$ / (unstimulated $\left.\left.\left(\mathrm{pg} \mathrm{ml}^{-1}\right)+1\right)\right]$.

The fold change for NHP samples was calculated as follows (in which $X=1,3,5$ or 7$)$ : $\mathrm{FC}=\left(\right.$ concentration $\left(\mathrm{pg} \mathrm{ml}^{-1}\right)$ on day $\left.X\right) /($ concentration

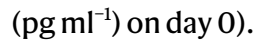




\section{Histology and immunohistochemistry}

Necropsies and tissue sampling were performed according to IBC-approved protocols. Lungs were perfused with $10 \%$ formalin and processed for histological review. Collected tissues were fixed for 8 days in $10 \%$ neutral-buffered formalin, embedded in paraffin, processed using a VIP-6 Tissue Tek (Sakura Finetek) tissue processor, and embedded in Ultraffin paraffin polymer (Cancer Diagnostics). Samples were sectioned at $5 \mu \mathrm{m}$, and resulting slides were stained with haematoxylin and eosin. Specific anti-CoV immunoreactivity was detected using a SARS-CoV-2 nucleocapsid protein rabbit antibody (Genscript) at a 1:1,000 dilution. The immunohistochemistry assay was carried out on a Discovery ULTRA automated-staining instrument (Roche Tissue Diagnostics) with a Discovery ChromoMap DAB (Ventana Medical Systems) kit. All tissue slides were evaluated by a board-certified veterinary anatomic pathologist blinded to study group allocations. In total, 18 sections taken from 6 different lung lobes were evaluated per animal; a representative lesion from each group was selected for Fig. 4.

\section{Statistical analyses}

Two-tailed Mann-Whitney $U$-tests or signed-rank Wilcoxon tests were conducted to compare differences between groups using Graphpad Prism version 8.3.0. A Bonferroni correction was used to control for type-I errors where required.

\section{Reporting summary}

Further information on research design is available in the Nature Research Reporting Summary linked to this paper.

\section{Data availability}

Data have been deposited in Figshare (https://figshare.com/articles/ dataset/Figshare_document_xlsx/12290696).
16. Bewig, B. \& Schmidt, W. E. Accelerated titering of adenoviruses. Biotechniques 28, 870-873 (2000).

17. Maizel, J. V. Jr, White, D. O. \& Scharff, M. D. The polypeptides of adenovirus. I. Evidence for multiple protein components in the virion and a comparison of types $2,7 \mathrm{~A}$, and 12 . Virology 36, 115-125 (1968).

18. Corman, V. M. et al. Detection of 2019 novel coronavirus (2019-nCoV) by real-time RT-PCR. Euro Surveill. 25, 2000045 (2020).

19. Wölfel, R. et al. Virological assessment of hospitalized patients with COVID-2019. Nature 581, 465-469 (2020)

20. Wrapp, D. et al. Cryo-EM structure of the 2019-nCoV spike in the prefusion conformation Science 367, 1260-1263 (2020).

Acknowledgements We thank O. Abiona, B. Bailes, A. Carmody, K. Corbett, K. Cordova, J. Faris, H. Feldmann, S. Gerber, B. Graham, E. Haddock, R. Kissinger, M. Jones, M. Marsh, K. Menk, A. Mora, S. Seifert, L. Shupert, B. Smith, N. Thornburg, A. Weidow, M. Woods and K. C. Yinda for their assistance during this study. This work was supported by the Intramural Research Program of the National Institute of Allergy and Infectious Diseases (NIAID), National Institutes of Health (NIH) (1ZIAAI001179-01) and the Department of Health and Social Care using UK Aid funding managed by the NIHR.

Author contributions N.v.D., T.L., S.C.G. and V.J.M. designed the study; N.v.D., T.L., A.S., S.B.-R J.N.P., J.R.P., V.A.A., T.B., A.F., M.U., F.F., E.R.A., H.S., J.S., M.H., A.O., K.M.-W., L.P.-P., N.J.E., D.W.,

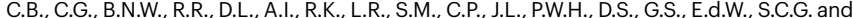
V.J.M. acquired, analysed and interpreted the data; N.v.D., T.L., E.d.W., S.C.G. and V.J.M. wrote the manuscript. All authors have approved the submitted version.

Competing interests S.C.G. is a board member of Vaccitech and named as an inventor on a patent covering the use of ChAdOx1-vector-based vaccines and a patent application covering a SARS-CoV-2 (nCoV-19) vaccine (UK patent application no. 2003670.3). T.L. is named as an inventor on a patent application covering a SARS-CoV-2 ( $\mathrm{nCoV}$-19) vaccine (UK patent application no. 2003670.3). The University of Oxford and Vaccitech, having joint rights in the vaccine, entered into a partnership with AstraZeneca in April 2020 for further development, large-scale manufacture and global supply of the vaccine. Equitable access to the vaccine is a key component of the partnership. Neither Oxford University nor Vaccitech will receive any royalties during the pandemic period or from any sales of the vaccine in developing countries. The other authors declare no competing interests.

Additional information

Supplementary information is available for this paper at https://doi.org/10.1038/s41586-0202608-y.

Correspondence and requests for materials should be addressed to S.C.G. or V.J.M Peer review information Nature thanks Wolfgang Baumgärtner and the other, anonymous, reviewer(s) for their contribution to the peer review of this work. Reprints and permissions information is available at http://www.nature.com/reprints. 
a
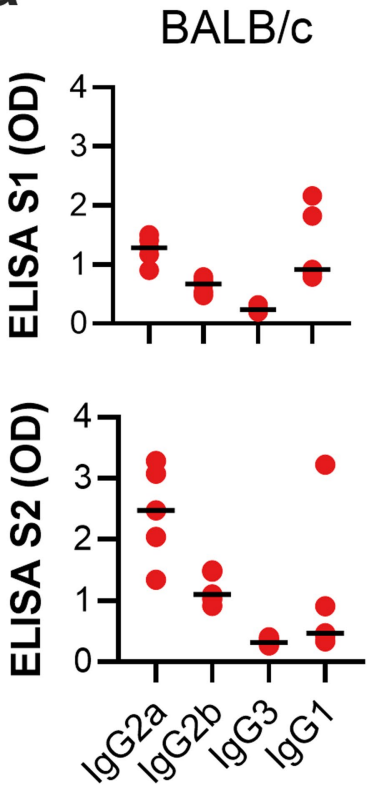

C
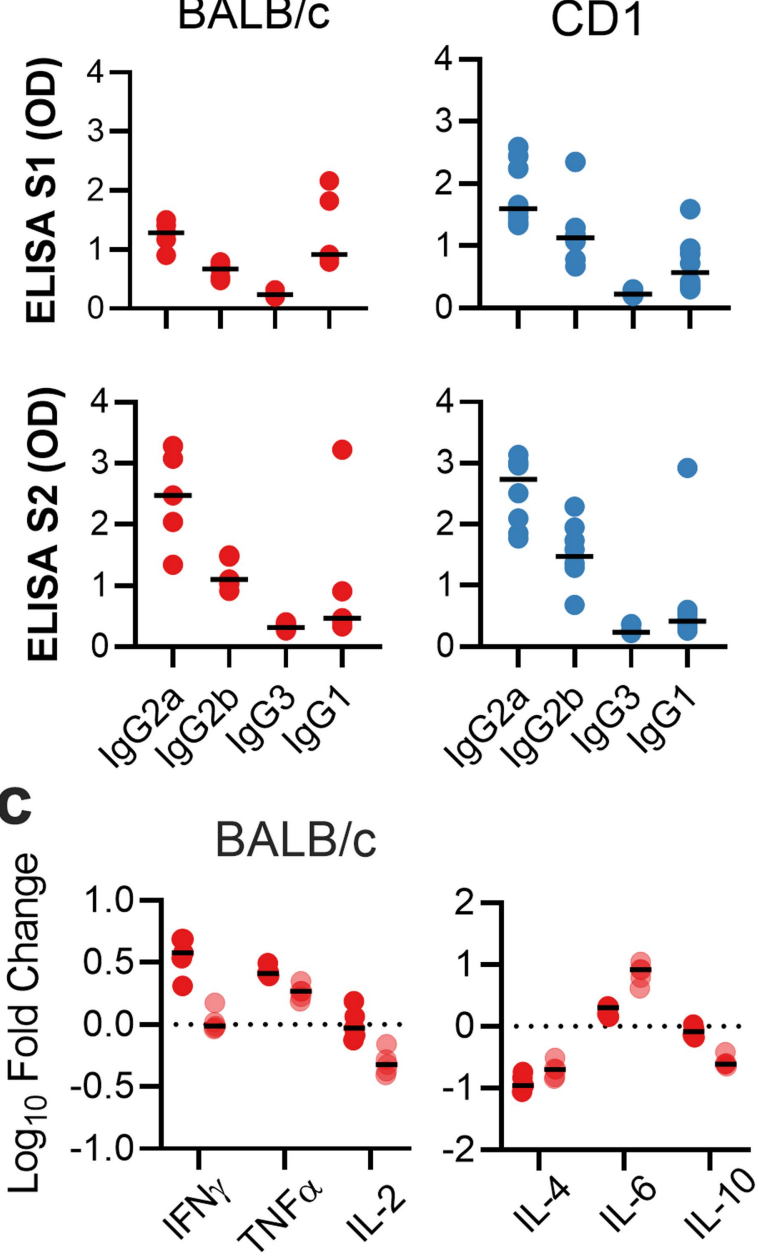

Extended Data Fig. 1 | Antigen-specific responses after ChAdOx1 nCov19 vaccination. a, IgG subclass antibodies detected against $S 1$ or $S 2$ protein in sera of BALB/c or CD1 mice. b, Frequency of cytokine-positive $\mathrm{CD}^{+}{ }^{+} \mathrm{T}$ cells after stimulation of splenocytes with S1-pool (solid colours) or S2-pool (transparent colours) peptides in BALB/c (red) and CD1 (blue) mice.c. The $\log _{10}$-transformed b
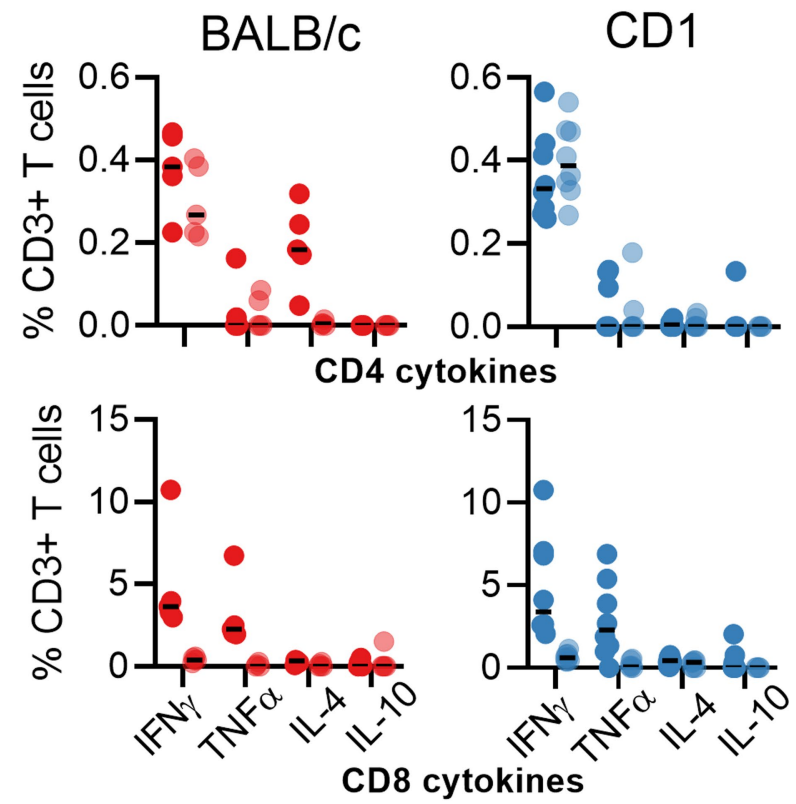

CD1
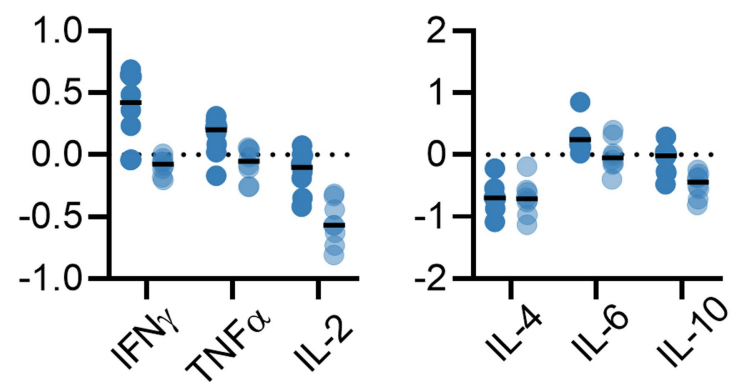

fold change in cytokine levels in supernatants from splenocytes stimulated with S1 (dark) or S2 (transparent) are shown in comparision to the corresponding unstimulated splenocyte samples for BALB/c and CD1 mice. a-c, $n=5(\mathrm{BALB} / \mathrm{c})$ and 8 (CD1) animals examined in a single independent experiment. 

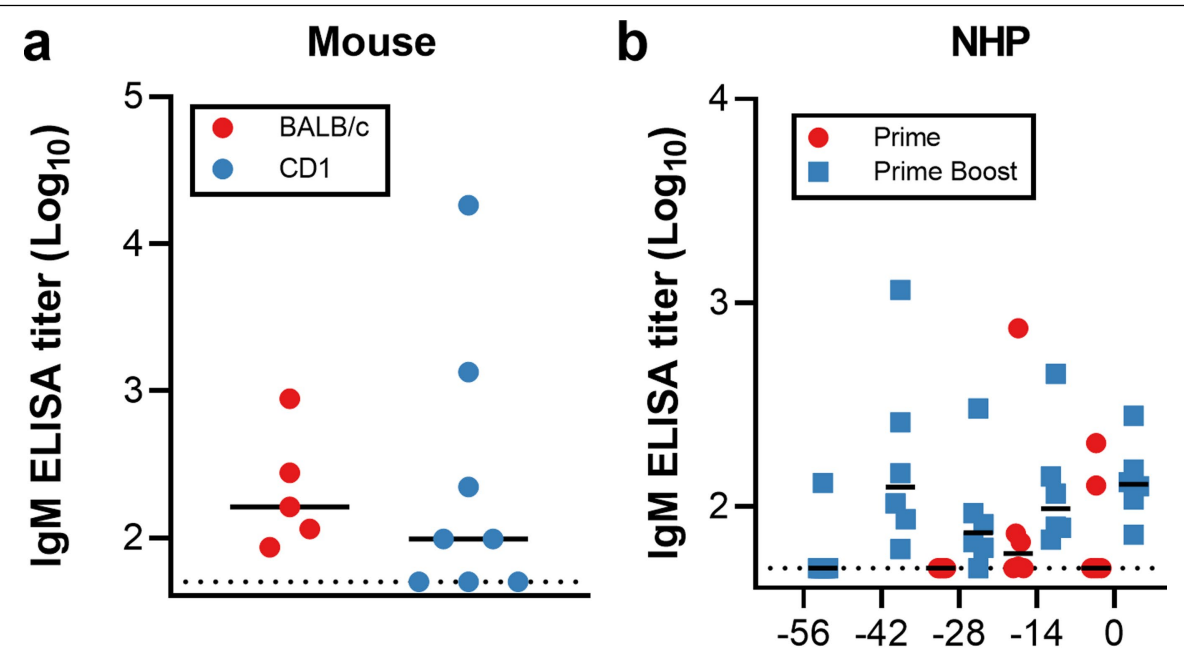

Days post inoculation

Extended Data Fig. 2 | Spike-specific serum IgM. a, Spike-specific serum IgM in mice 14 days after vaccination. $n=5(\mathrm{BALB} / \mathrm{c})$ and $8(\mathrm{CD} 1)$ mice examined in a single independent experiment. b, Spike-specific serum IgM in NHPs after

prime-boost or prime-only vaccination. $n=6$ animals per group examined in 2 independent experiments. 


\section{Article}

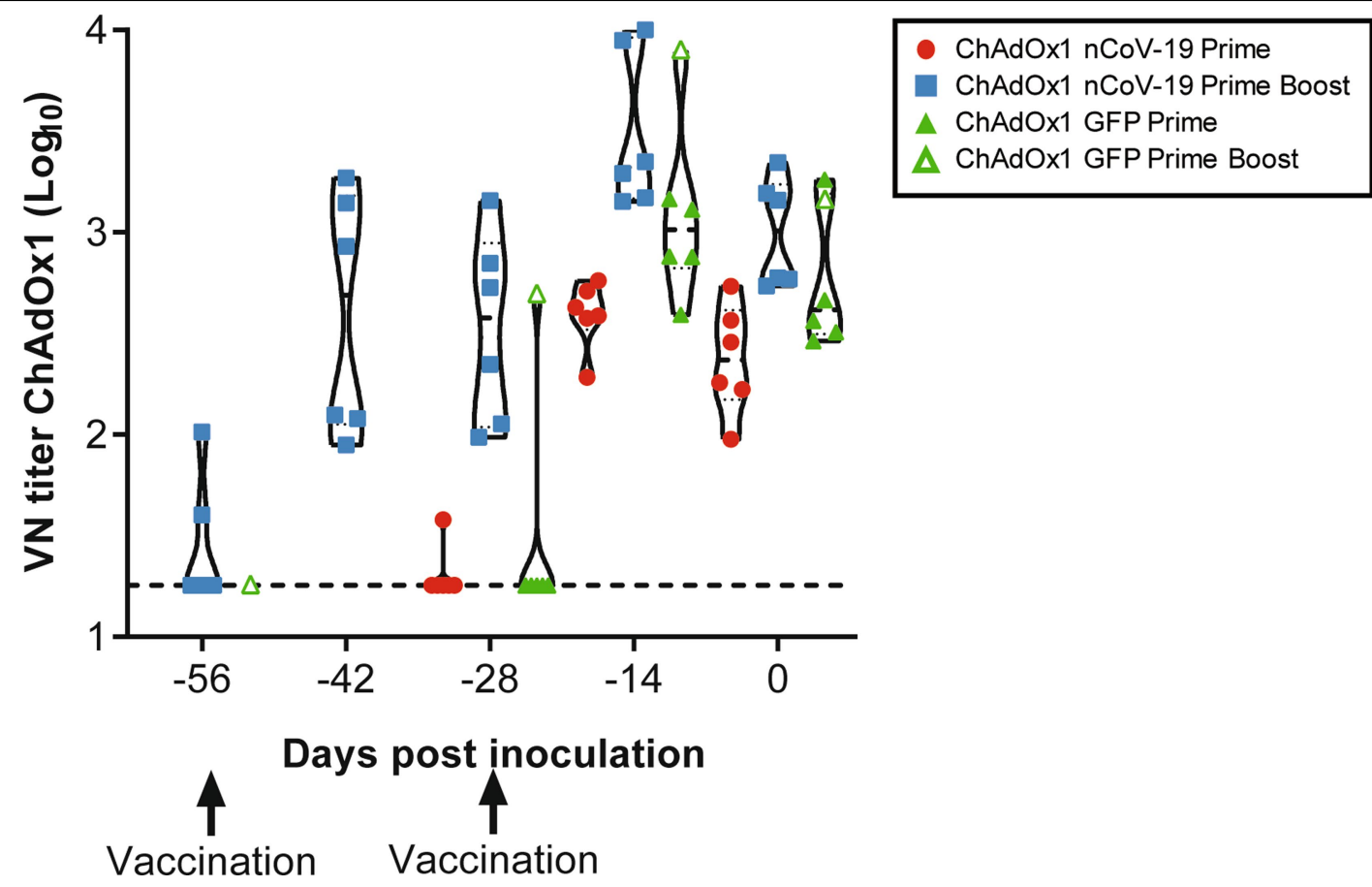

Extended Data Fig. 3 | ChAdOx1 neutralizing antibodies in serum of vaccinated NHPs. The control NHP treated with the prime-boost regimen is shown as an open triangle. $\mathrm{VN}$, virus neutralizing. $n=6$ animals per group examined in 2 independent experiments. 

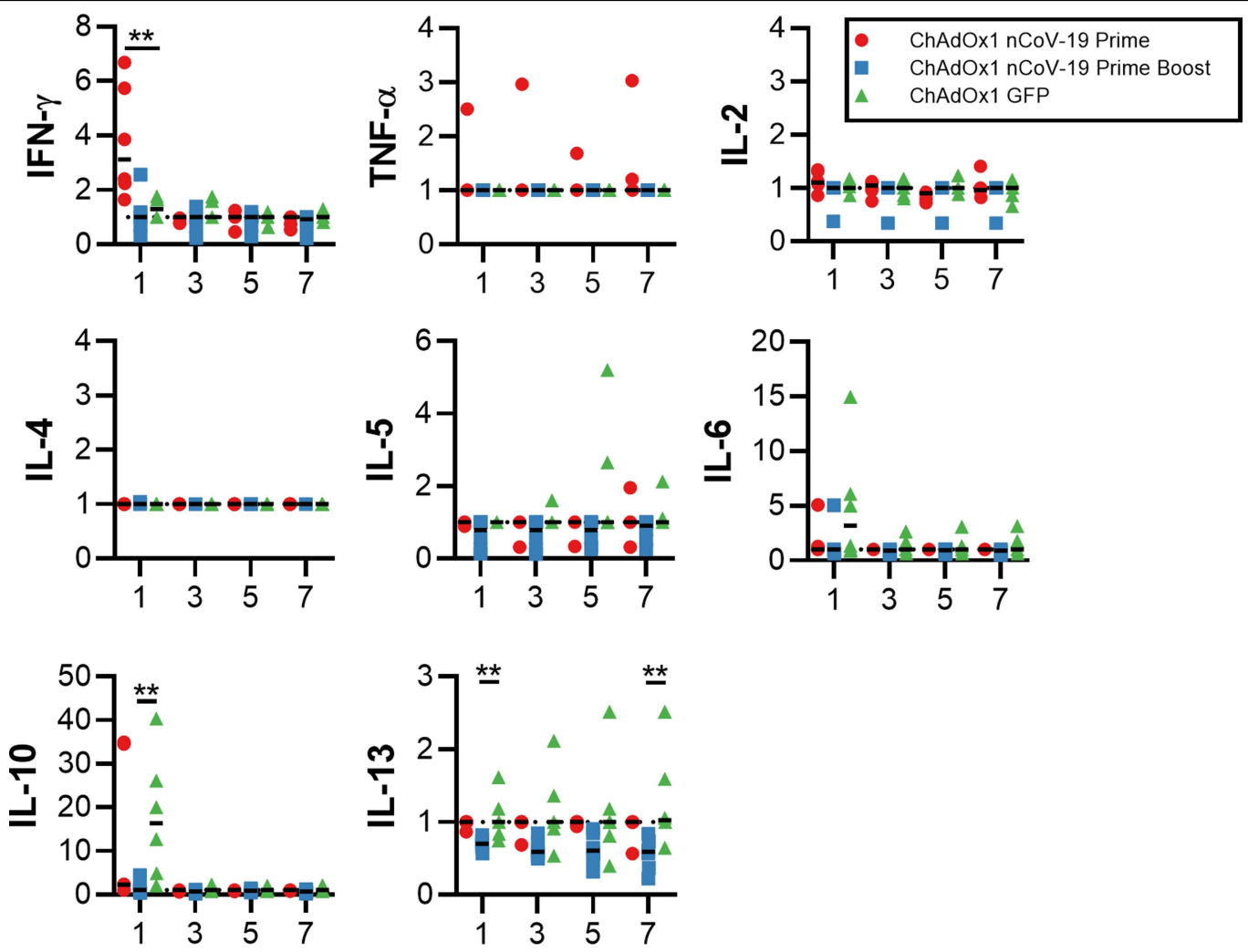

Extended Data Fig. 4 | Serum cytokines in rhesus macaques challenged with SARS-CoV-2. Fold increase in cytokines in serum compared to prechallenge values. ${ }^{* *} P<0.01$. the lines indicate the median. Statistical significance was determined by two-tailed Mann-Whitney $U$-test. $P$ values for the different cytokines were: IFN $\gamma, P=0.0087$; IL-10, $P=0.0043$; IL-13, $P=0.0043$ (left) and $P=0.0065$ (right). $n=6$ animals per group examined in 2 independent experiments. 
- ChAdOx1 nCoV-19 Prime

- ChAdOx1 nCoV-19 Prime Boost

$\triangle$ ChAdOx1 GFP

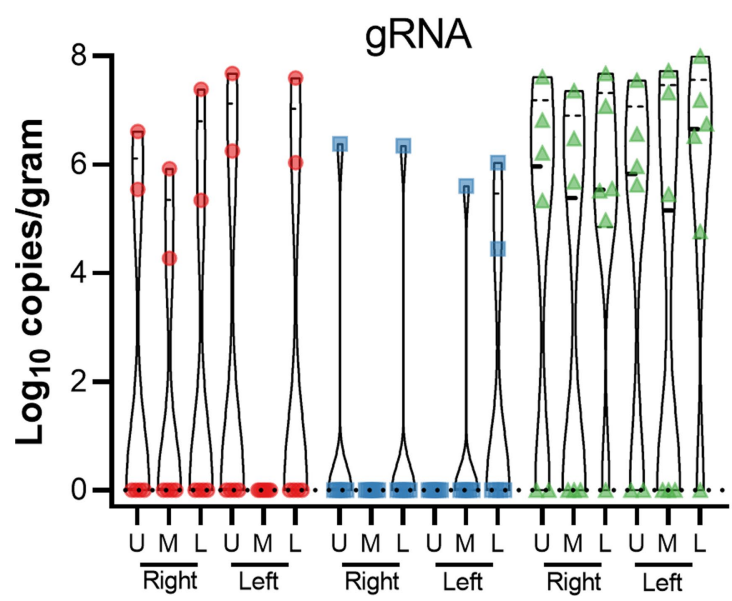

sgRNA

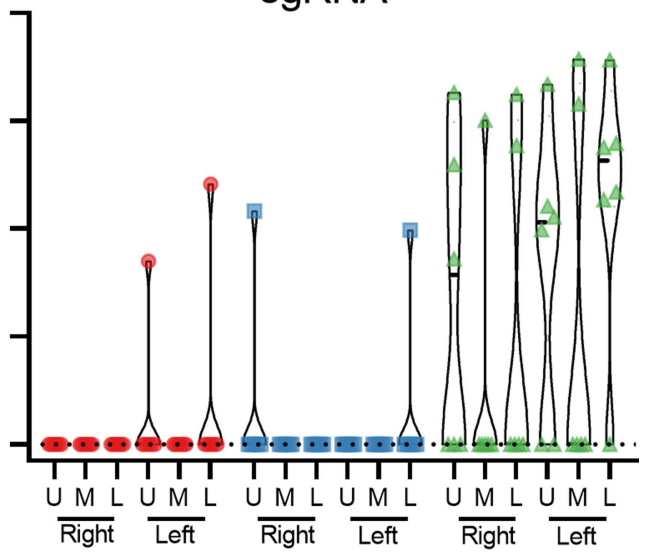

Extended Data Fig. 5 | Viral load in lung tissue of rhesus macaques challenged with SARS-CoV-2 at 7 d.p.i. Viral gRNA (left) and sgRNA (right) in lung tissues. 
- ChAdOx1 nCoV-19 Prime

ChAdOx1 nCoV-19 Prime Boost

$\triangle$ ChAdOx1 GFP

a

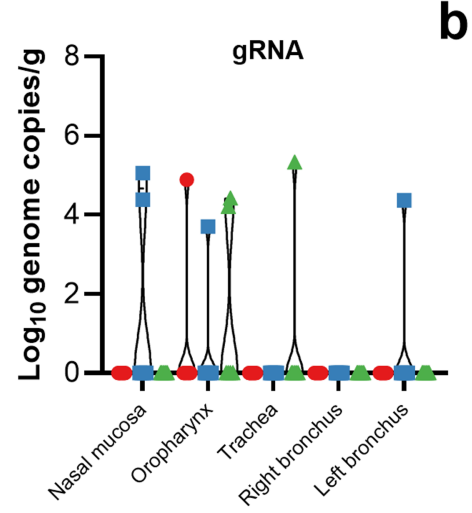

C

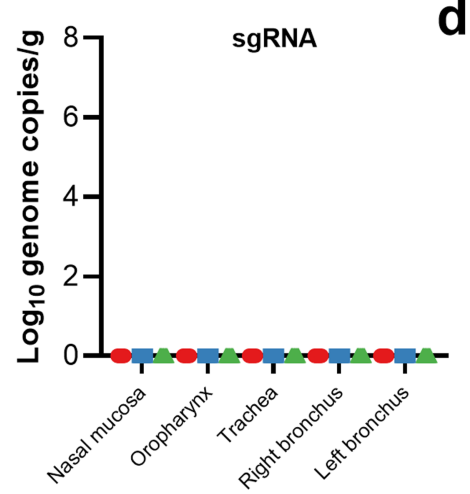

b

d
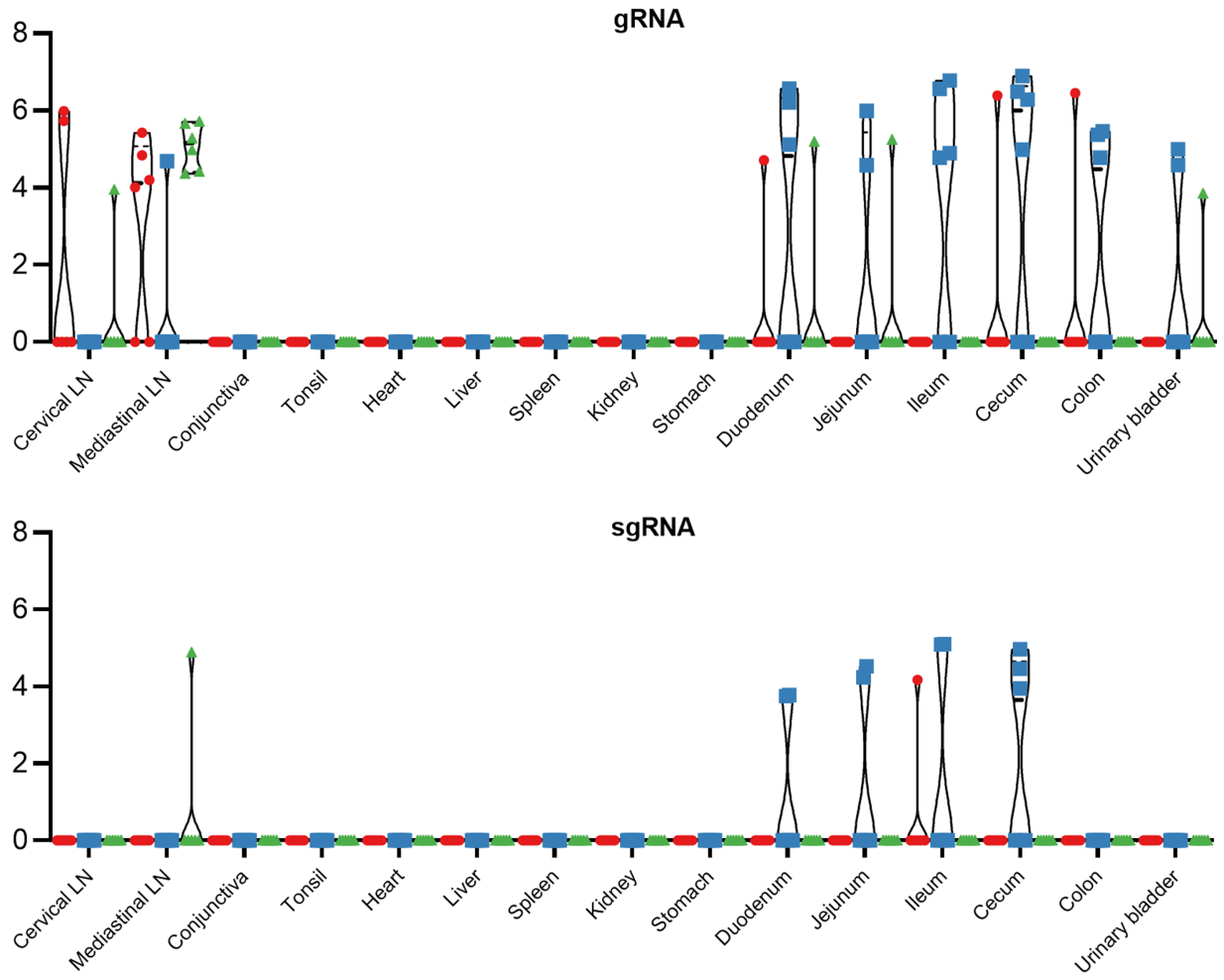

Extended Data Fig. 6 | Viral load in tissues of rhesus macaques challenged with SARS-CoV-2 at 7 d.p.i. a, Viral gRNA in respiratory tissues excluding lung tissue. b, Viral gRNA in non-respiratory tissues. c, Viral sgRNA in respiratory tissues excluding lung tissue.d, Viral sgRNA in non-respiratory tissues. 


\section{Article}

Extended Data Table 1 | Virus isolation from nasal swabs

\begin{tabular}{cccc}
\hline & $\begin{array}{c}\text { ChAdOx1 nCoV- } \\
\text { 19 Prime }\end{array}$ & $\begin{array}{c}\text { ChAdOx1 nCoV- } \\
\text { 19 Prime-boost }\end{array}$ & $\begin{array}{c}\text { ChAdOx1 } \\
\text { GFP }\end{array}$ \\
\hline 1 DPI & $4 / 6$ & $2 / 6$ & $4 / 6$ \\
3 DPI & $2 / 6$ & $0 / 6$ & $1 / 6$ \\
5 DPI & $0 / 6$ & $0 / 6$ & $0 / 6$ \\
7 DPI & $0 / 6$ & $0 / 6$ & $0 / 6$ \\
\hline
\end{tabular}

Virus was isolated from nasal swabs of rhesus macaques after challenge with SARS-CoV-2. 


\section{natureresearch}

Corresponding author(s): Vincent Munster

Last updated by author(s): 7/21/2020

\section{Reporting Summary}

Nature Research wishes to improve the reproducibility of the work that we publish. This form provides structure for consistency and transparency in reporting. For further information on Nature Research policies, see Authors \& Referees and the Editorial Policy Checklist.

\section{Statistics}

For all statistical analyses, confirm that the following items are present in the figure legend, table legend, main text, or Methods section.

n/a Confirmed

$\square$ The exact sample size $(n)$ for each experimental group/condition, given as a discrete number and unit of measurement

Х $\square$ A statement on whether measurements were taken from distinct samples or whether the same sample was measured repeatedly

The statistical test(s) used AND whether they are one- or two-sided

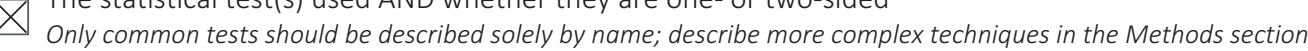

$\bigotimes \square$ A description of all covariates tested

$\square$ A description of any assumptions or corrections, such as tests of normality and adjustment for multiple comparisons

$\triangle$ A full description of the statistical parameters including central tendency (e.g. means) or other basic estimates (e.g. regression coefficient)

$\triangle$ AND variation (e.g. standard deviation) or associated estimates of uncertainty (e.g. confidence intervals)

$\square$ For null hypothesis testing, the test statistic (e.g. $F, t, r$ ) with confidence intervals, effect sizes, degrees of freedom and $P$ value noted

Give P values as exact values whenever suitable.

Х $\square$ For Bayesian analysis, information on the choice of priors and Markov chain Monte Carlo settings

Х For hierarchical and complex designs, identification of the appropriate level for tests and full reporting of outcomes

$\bigotimes \square$ Estimates of effect sizes (e.g. Cohen's $d$, Pearson's $r$ ), indicating how they were calculated

Our web collection on statistics for biologists contains articles on many of the points above.

\section{Software and code}

Policy information about availability of computer code

\section{Data collection No software was used.}

Data analysis Data were analyzed using Graphpad Prism V8.3.0, FlowJo V10, and CTL ImmunoSpot ${ }^{\circledR} 7.0 .11 .0$ Professional Analyzer DC

For manuscripts utilizing custom algorithms or software that are central to the research but not yet described in published literature, software must be made available to editors/reviewers. We strongly encourage code deposition in a community repository (e.g. GitHub). See the Nature Research guidelines for submitting code \& software for further information.

\section{Data}

Policy information about availability of data

All manuscripts must include a data availability statement. This statement should provide the following information, where applicable:

- Accession codes, unique identifiers, or web links for publicly available datasets

- A list of figures that have associated raw data

- A description of any restrictions on data availability

\section{Field-specific reporting}

Please select the one below that is the best fit for your research. If you are not sure, read the appropriate sections before making your selection.
Х Life sciences
Behavioural \& social sciences Ecological, evolutionary \& environmental sciences 


\section{Life sciences study design}

All studies must disclose on these points even when the disclosure is negative.

Sample size NHP - Since this is a model with no prior data, it was not possible to perform a power analysis. The sample size was based on experience with other nonhuman primate models of respiratory disease where the numbers used were sufficient for statistical analyses.

Mice - Sample size was determined based on previous experience measuring the immunogenicity of vaccines in inbred and outbred mice where the numbers used were sufficient for statistical analyses.

Data exclusions No data were excluded.

Replication Lung histology: for each animal ( $\mathrm{n}=12$ (vaccinated) or 6 (control)), 3 sections were evaluated from all 6 lung lobes.

Cytokine analysis: serum samples were analyzed in duplicate from each animal for each timepoint; $n=12$ (vaccinated) or 6 (control) Serological analysis: Serum samples were analyzed in duplicate from each animal for each timepoint; $\mathrm{n}=12$ (vaccinated) or 6 (control). Mouse experiments were repeated twice

All repeats were successful. qRT-PCR assays were performed with in-house validated standards. Flow cytometry and ELISpot assays were performed with positive controls (PMA/IONO stimulation).

Randomization Animals were randomly assigned to groups

Blinding Blinding was done for the following personnel:

- Person scoring animals daily

- Veterinary pathologists reviewing histology

- Clinical veterinarians performing exams

\section{Reporting for specific materials, systems and methods}

We require information from authors about some types of materials, experimental systems and methods used in many studies. Here, indicate whether each material, system or method listed is relevant to your study. If you are not sure if a list item applies to your research, read the appropriate section before selecting a response.

Materials \& experimental systems

\begin{tabular}{l|l}
\hline$n / a$ & Involved in the study \\
$\square$ & $\bigotimes$ Antibodies \\
$\square$ & $\square$ Eukaryotic cell lines \\
$\square$ & $\square$ Palaeontology \\
$\square$ & $\square$ Animals and other organisms \\
$\square$ Clinical data
\end{tabular}

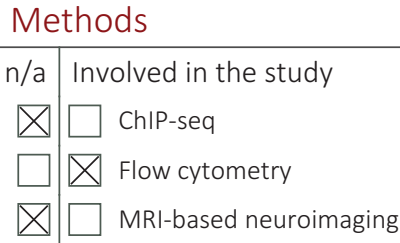

\section{Antibodies}

in-house SARS-2 rabbit sera, GenScript

CD4-BUV496, BD, cat\#557984, clone 500A2, dilution 1 in 100

CD8-PerCPCy5.5, BD, cat\# 564667, clone GK1.5, dilution 1 in 100

CD62L-BV711, eBioscience/Thermofisher, cat\# 45-0081-82, clone 53-6.7, dilution 1 in 200

CD127-BV650, BioLegend, cat\# 103028, clone IM7, dilution 1 in 100

TNF-a-A488, BioLegend, cat\# 104445, clone MEL-14, dilution 1 in 100

IL-2-PECy7, BioLegend, cat\# 121610, clone 1D4B, dilution 1 in 1000

IL-4-BV605, BioLegend, cat\# 135043, clone A7R34, dilution 1 in 100

IL-10-PE, eBioscience/Thermofisher, cat\# 48-7311-82, clone XMG1.2, dilution 1 in 100

IFN-g-e450, eBioscience/Thermofisher, cat\# 25-7021-82, clone JES6-5H4, dilution 1 in 100

anti-monkey IgG (gamma) antibody, peroxidase-labeled, Seracare, cat\# 5220-0333/074-11-021, Lot\# 10329492, dilution 1:2500

anti-monkey IgM antibody, peroxidase-labeled, Rockland, cat\# 617-105-007, Lot\# 27986, dilution 1:5000

anti-mouse IgM antibody, peroxidase-labeled, Abcam, cat\# ab98672, Lot\# GR325319-6, dilution 1:5000

Alkaline Phosphatase-conjugated goat anti-mouse IgG, Sigma, cat\# A3562, Lot\# SLBK6489v, dilution 1:5000

Validation of cross-reactivity of SARS-CoV to SARS-CoV-2 in IHC was done in-house by embedding SARS-CoV-2 infected Vero cells in histogel and producing and staining histology slides.

All other antibodies validated by supplier:

Monkey IgM: Assay by immunoelectrophoresis resulted in a single precipitin arc against anti-Alkaline Phosphatase (calf intestine), anti-Goat Serum, Monkey IgM and Monkey Serum. No reaction was observed against other Monkey heavy or light chain proteins.

Mouse IgM: Minimal cross-reactivity Human, Rat

Mouse IgG: Anti-Mouse IgG (whole molecule)-Alkaline Phosphatase antibody is specific for normal mouse serum and mouse IgG. In Ouchterlony double diffusion assays, the antibody reacts with mouse $\lg G 1, \lg G 2 \mathrm{a}, \lg G 2 \mathrm{~b}, \lg G 3$, $\lg \mathrm{A}$, and $\lg \mathrm{M}$. 


\section{Eukaryotic cell lines}

Policy information about cell lines

Cell line source(s)

VeroE6: Ralph Baric, University of North Carolina, Chapel Hill, USA (not commercial)

GripTite 293 MSR cell line: ThermoFisher, Cat\# R79507

T-Rex-293 cell line: ThermoFisher, Cat\# R71007

Authentication

Not authenticated in-house.

Mycoplasma contamination

Mycoplasma testing confirmed negative at regular intervals.

Commonly misidentified lines

(See ICLAC register)

No commonly misidentified cell lines were used.

\section{Animals and other organisms}

Policy information about studies involving animals; ARRIVE guidelines recommended for reporting animal research

Laboratory animals

Rhesus macaques, Chinese origin, adult (2-6 years), 17 males, 1 female

Mice - Female BALB/COlaHsd (BALB/c) (Envigo) and outbred Crl:CD1(ICR) (CD1) (Charles River) mice of at least 6 weeks of age

Wild animals

No wild animals were used.

Field-collected samples

No samples were collected in the field.

Ethics oversight

Mice - Mice were used in accordance with the UK Animals (Scientific Procedures) Act under project license number P9804B4F1 granted by the UK Home Office.

NHP - All animal experiments were approved by the Institutional Animal Care and Use Committee of Rocky Mountain

Laboratories, NIH and carried out by certified staff in an Association for Assessment and Accreditation of Laboratory Animal Care (AAALAC) International accredited facility, according to the institution's guidelines for animal use, following the guidelines and basic principles in the NIH Guide for the Care and Use of Laboratory Animals, the Animal Welfare Act, United States Department of Agriculture and the United States Public Health Service Policy on Humane Care and Use of Laboratory Animals.

Note that full information on the approval of the study protocol must also be provided in the manuscript.

\section{Flow Cytometry}

Plots

Confirm that:

$\bigotimes$ The axis labels state the marker and fluorochrome used (e.g. CD4-FITC).

\The axis scales are clearly visible. Include numbers along axes only for bottom left plot of group (a 'group' is an analysis of identical markers).

\All plots are contour plots with outliers or pseudocolor plots.

$\bigotimes$ A numerical value for number of cells or percentage (with statistics) is provided.

\section{Methodology}

Sample preparation

Instrument

Software

Cell population abundance

Gating strategy

\Tick this box to confirm that a figure exemplifying the gating strategy is provided in the Supplementary Information.

Sample preparation: Single cell suspension of murine splenocytes were prepared by passing cells through $70 \mu \mathrm{M}$ cell strainers and ACK lysis prior to resuspension in complete medium. Cells were stimulated at 37oC for 6 hours with $2 \mu \mathrm{g} / \mathrm{ml} \mathrm{S1} \mathrm{or} \mathrm{S2} \mathrm{pools} \mathrm{of}$ peptide, media or cell stimulation cocktail (containing PMA-Ionomycin, Biolegend), together with $1 \mu \mathrm{g} / \mathrm{ml}$ Golgi-plug (BD) with the addition of $2 \mu \mathrm{l} / \mathrm{ml}$ CD107a-Alexa

BD Fortessa X2

BD FACSDiva Software Version 8.0.2, FlowJo version 10 for analysis

An acquisition threshold was set at a minimum of 5000 events in the live CD3+ gate

Antigen specific T cells were identified by gating on LIVE/DEAD negative, doublet negative (FSC-H vs FSC-A), size (FSC-H vs SSC), $\mathrm{CD} 3+, \mathrm{CD} 4+$ or $\mathrm{CD} 8+$ cells and cytokine positive. Cytokine positive responses are presented after subtraction of the background response detected in the corresponding unstimulated sample (media containing CD107a and Golgi-plug) of each individual spleen sample. 